\title{
Access to denture restoration services under removable dentures subsidy program for adults aged 65 years and older in Taiwan- an interpretive approach
}

Kuan-Yu Chu ${ }^{1,2^{*}}$

\begin{abstract}
Background: Access is an important issue in health equality. Availability of dental services and cost subsidies is an important factor affecting access to denture restoration for the elderly. This study aims to explore access to denture restoration services in the elderly removable denture's subsidy program of Taiwan.
\end{abstract}

Methods: Access to the elderly removable dentures subsidy program was measured from two aspects, that is, availability of subsidies and payment for these services and the characteristics of patients and their treatment needs. The first aspect included reimbursements and the number and location of subsidy clinics, and the second aspect included the age and gender distribution of patients and denture types. Information on reimbursement regulations and the number and location of dental clinics providing subsidized services were obtained from the website of the Taoyuan City Public Health Bureau, Taoyuan Hospital, Department of Statistics and Ministry of Health and Welfare. Data on patient characteristics and denture type were obtained through a retrospective survey. We selected individuals who participated in the elderly removable denture's subsidy program from 2015 to 2018 at the Geriatric Dentistry Department of Taoyuan Hospital. We conducted data analysis using an interpretive approach.

Results: This study found that reimbursement amounts are inadequate, and the availability of subsidized services is low. Moreover, the proportion of male applications is slightly higher than that of females. In addition, among the applicants, removable partial dentures for single or two arches are the most common.

Conclusions: Problems of insufficient numbers of contracted hospitals and low reimbursement amounts are observed in the subsidy program, which are the key factors affecting access to denture restoration services among the elderly. Policymakers should exclude wealthy individuals and offer subsidy only to low-income elderly individuals with missing teeth who are in dire need of financial support to improve their dental health.

Keywords: Access, Removable dentures, Government subsidy, Geriatric dentistry

*Correspondence: kyc0321@gmail.com; dba15@tpech.gov.tw ${ }^{1}$ Department of Stomatology, Taipei City Hospital Renai Branch, 10629 No. 10, Section 4, Renai Road, Daan District, Taipei City, Taiwan Full list of author information is available at the end of the article

\section{Background}

Access is an important issue in health equality and defined as the degree of fitness between patients and providers [1]. Since 1974, numerous scholars have proposed specific dimensions for measuring access, that is, the three dimensions of system and patient characteristics and access indicators. In addition, the 
measurement indices of access include availability, accessibility, acceptability, affordability, and adequacy [1-4]. Saurman later extended this theoretical framework to include awareness [5].

Population aging is increasing in developed and developing countries [6]. Concerns about population aging stem mainly from older people who require increased medical services [7]. Economic analyses focused on the financial impact of aging, which is expected to increase the burden on health and welfare services [8]. Specifically, low dental rehabilitation rates in an aging population mean that elderly individuals will require dental services [9]. Severe tooth loss and edentulism in older individuals are very common [10]. Among the elderly, systemic pathologies that reduce motor skills are common. Therefore, multidisciplinary management of the elderly should include oral care and rehabilitation to improve their quality of life [11]. Moreover, the nutrition status and quality of life of older adults are adversely affected when their missing teeth are not replaced $[12,13]$.

Removable dentures are an economical and affordable option for older individuals with missing teeth [14]. However, financial considerations may hinder older individuals from seeking medical treatment and obtaining dentures, thereby creating a gap in equitable medical treatment [15]. In Europe and the United States, the availability of dental services and price subsidies for dental treatments are important factors that affect access to dental care services for older adults [16]. In Europe and the United States, the availability of dental services and cost subsidies for dental treatment is an important factor affecting access to dental care services for older adults [17]. Evidence shows that older individuals are willing to avail dental services if government subsidies are available $[16,18,19]$.

According to the 2012 National Health Interview Survey of the United States, $17.5 \%$ of individuals aged 65-74 years had missing teeth. This rate was $25.8 \%$ for individuals over the age of 75 years [20]. Taiwan's oral condition survey in 2016 indicated that the average number of natural teeth in individuals between the ages of 65 and 74 years was 20.82 . In this age group, the proportion of edentulous men was $35.6 \%$ and that of edentulous women was $32.4 \%$. Among individuals over the age of 75 years, the average number of natural teeth was 16.71 . Moreover, in this age group, $45.2 \%$ of men were edentulous, and $54.4 \%$ of women were edentulous [21]. In Taiwan, the prevalence of missing teeth is higher among women than among men, which was similarly observed in a US study [17]. Tsai (2003) pointed out that more than half of the population over the age of 65 years in Taiwan require new dental prostheses [22].
Taiwan became an aged society in 2018, and at the end of December 2019, the proportion of the population over the age of 65 years was $15.28 \%$ or approximately 3.6 million. However, the municipality of Taoyuan is relatively young, with only $12.11 \%$ of the population (approximately 272,000 individuals) over the age of 65 years [23]. Taoyuan is one of the few cities in Taiwan that provides a subsidy to non-low-income elderly individuals for removable dentures and thus is a suitable research setting. This study aims to explore access to dental restoration services in the elderly removable dentures subsidy program and establish an evaluation model of this medical policy to provide decision makers with a reference for improvement.

\section{Method and materials}

This study focuses on the gap in access to denture restoration services and uses Penchansky and Thomas's modified theory of access as the study design [1]. We measured access to the elderly removable dentures subsidy program from two aspects, that is, availability of subsidies and payment for these services and the characteristics of patients and their treatment needs. The first aspect included reimbursements and the number and location of subsidy clinics, and the second aspect included the age and gender distribution of patients and denture types.

Information on reimbursement regulations and the number and location of dental clinics providing subsidized services were obtained from the website of the Taoyuan City Public Health Bureau, Taoyuan Hospital, Department of Statistics and Ministry of Health and Welfare $[24,25]$.

To obtain information on patient characteristics and the denture type, we retrospectively investigated the individuals who participated in the elderly removable denture's subsidy program for the period of 2015-2018 at the Geriatric Dentistry Department of Taoyuan Hospital. The individuals who participated in this program underwent an oral examination, and those who met the requirements were given removable dentures. The requirements for the participants were as follows: at least 65 years old with more than four missing teeth in a single jaw or more than two missing teeth with a free-end saddle, not including the third molar. In this survey, the following inclusion criteria were used: 1) a geriatric dentistry patient at Taoyuan Hospital during the period of $2015-2018$; 2) completed the application procedure to participate in the removable dentures subsidy program for the elderly, specifically, underwent an oral examination, accomplished the application form and paid the application fee; and 3) completed the process, from the fabrication to the delivery of the removable dentures. The exclusion criteria included the following: 1) subsidy 
recipients under the age of 65 years, 2) applicants who failed to complete the delivery step by 31 December 2018 and 3) self-financed cases. Each subsidy applicant was required to complete the following steps: undergo an oral examination, accomplish the application form and submit the application form to the Municipal Public Health Bureau. All the participants provided informed consent. After the application process, the removable dentures were fabricated and delivered to the applicants, who were required to complete a satisfaction survey. The applicant's name, gender, age, denture type, application fee amount and removable denture design were the most important items on the application form. In the present study, we obtained the oral examinations and application forms with information on denture type, application fee amount and design of the removable dentures. Dental assistants were responsible for administrative duties and taking photographs of participants with preoperative and postoperative dentures.

For the statistical analysis, IBM SPSS version 21 was used (IBM Corp., Armonk, NY, USA). Data analysis was conducted using an interpretive approach, as is customary in policy analysis. The Taipei City Hospital Research Ethics Committee approved the study protocol. (Grant numbers TCHIRB-11002013-E).

\section{Results}

The single-jaw removable partial dentures (RPDs) subsidy is NT 15,000 (approximately USD 500). An RPD with fewer than three remaining teeth per jaw and the single-jaw complete dentures subsidy are NT 20,000 (approximately USD 667).

At the end of 2017, Taoyuan City had 13 administrative districts, and 151 dental clinics were contracted to provide subsidized services (availability) in the 13 administrative districts (accessibility). At the time, Taoyuan City had a total of 488 dental clinics (including hospitals).

In the retrospective survey, 432 applications were received during the study period, excluding five patients under the age of 65 years and four who failed to complete the entire process by the end of 2018 . The individuals who obtained removable dentures at their own expense are excluded from the study. Thus, a total of 423 eligible individuals are included. Among them, $54.4 \%$ are male, and $45.6 \%$ are female, and the mean age is 76.3 years. Tables 1 and 2 shows that overall, the applications for both-jaw dentures (64.5\%) outnumber those for single-jaw prostheses. In terms of the age group, the 65-74 years group (42.8\%) is the largest, followed by the $75-84$ years group (38.5\%). The survey also shows that among those who applied for a single-jaw dentures subsidy, those who applied for RPDs
Table 1 Characteristics who participated elderly removable dentures subsidy program in Geriatrics Dentistry of Taoyuan Hospital, 2015-2018, $n=423$

\begin{tabular}{|c|c|c|c|c|c|}
\hline & \multirow[t]{2}{*}{ Age } & \multicolumn{2}{|l|}{ Gender } & \multirow[t]{2}{*}{ Total } & \multirow[t]{2}{*}{$p$-value $\dagger$} \\
\hline & & Female & Male & & \\
\hline \multirow{5}{*}{ Applied Single Arch } & $65-74$ & 39 & 30 & 69 & \multirow[t]{5}{*}{0.003} \\
\hline & $75-84$ & 30 & 31 & 61 & \\
\hline & $85-94$ & 4 & 15 & 19 & \\
\hline & 95 & 0 & 1 & 1 & \\
\hline & Total & 73 & 77 & 150 & \\
\hline \multirow[t]{4}{*}{ Applied Both Arches } & $65-74$ & 50 & 62 & 112 & \multirow[t]{4}{*}{$<0.001$} \\
\hline & $75-84$ & 56 & 46 & 102 & \\
\hline & $85-94$ & 14 & 45 & 59 & \\
\hline & Total & 120 & 153 & 273 & \\
\hline \multirow[t]{5}{*}{ Total } & $65-74$ & 80 & 92 & 181 & \\
\hline & $75-84$ & 86 & 77 & 163 & \\
\hline & $85-94$ & 18 & 60 & 78 & \\
\hline & 95 & 0 & 1 & 1 & \\
\hline & Total & 193 & 230 & 423 & \\
\hline
\end{tabular}

${ }^{\dagger}$ Pearson's Chi-square Test for Independence

Table 2 Denture types who applied removable dentures subsidy in Geriatrics Dentistry of Taoyuan Hospital, 2015-2018, $n=423$

\begin{tabular}{llll}
\hline & Type & Times & Percent (\%) \\
\hline Applied Single Arch $n=150$ & LC & 15 & 10.0 \\
& LR & 46 & 30.7 \\
& LH & 6 & 4.0 \\
& UC & 17 & 11.3 \\
& UR & 50 & 33.3 \\
& UH & 16 & 10.7 \\
& Total & 150 & 100 \\
Applied Both Arches $n=273$ & BC & 64 & 23.4 \\
& BR & 65 & 23.8 \\
& BH & 16 & 5.9 \\
& UCLR & 26 & 9.5 \\
& UCLH & 20 & 7.3 \\
& URLC & 20 & 7.3 \\
& URLH & 19 & 7.0 \\
& UHLC & 20 & 7.3 \\
& UHLR & 23 & 8.4 \\
& Total & 273 & 100 \\
\hline
\end{tabular}

U Upper arch, $L$ Lower arch, $C$ Complete denture, $R$ RPD (Removable Partial Denture), $H$ RPD with remaining teeth $\leqq 3, B$ Both arches

account for the majority (64\%), particularly upper-jaw RPDs (approximately one-third). Among the participants who applied for a both-arch dentures subsidy, the 
majority applied for both-arch full-mouth dentures and both-arch RPDs, which are both more than $20 \%$.

\section{Discussions}

This study measures the reimbursement of services, location and number of clinics providing subsidized services, the demographic characteristics of the participants and the denture type to evaluate access to removable dentures for the elderly. This study finds that a reimbursement of NT 15,000 is provided for RPDs, which is equivalent to $37.5 \%$ of the self-financed price in the hospital. Moreover, a reimbursement of NT 20,000 is given for complete or half dentures (remaining teeth $\leqq 3$ ), which is equivalent to $40 \%$ of the self-financed price in the hospital. From this point of view, the reimbursement system is inadequate. Among the 13 administrative regions of Taoyuan City, at least one contracted institution in each administrative region provides subsidized services and demonstrates satisfactory accessibility. Among the 488 dental clinics in the city, only 151 are willing to sign a subsidy contract, and availability is approximately $30 \%$, which can be regarded as average. From the above two points, cost reimbursements and availability of dental services are important factors affecting access to denture restoration. These findings appear to be generally compatible with the results of previous studies [16].

The survey results show that the proportion of male applications is slightly higher than that of females, which is different in the general population of Taiwan, where older women have more missing teeth than older men [21]. The reason for this finding may be that men with missing teeth are relatively young and can easily go to the hospital to apply for a removable dentures subsidy. These results may also be a consequence of inadequate information on the subsidy provided to the public or insufficient medical institutions participating in the subsidy program.

In terms of the denture type, RPDs are the most common among the single-arch applicants, and RPDs and full dentures are the most common among the both-arch applicants. Some patients chose acrylic dentures, for which the reimbursement amount is the same as that for RPDs with a metal frame. High satisfaction is reported for both types of dentures, as reported in previous studies $[26,27]$. Given the restrictions on the types of subsidized dentures, some patients experienced dry mouth or severe atrophy in the alveolar bone of their lower jaw. They complained that the complete denture retention was insufficient but lacked financial resources to obtain implant-supported removable dentures [28-30].

The study aims to provide suggestions for this subsidy policy and establish an evaluation model for similar policies. The findings of this study can help policymakers improve the removable dentures subsidy program for older adults. The Taiwanese government implemented the subsidy program for older individuals with missing teeth to help solve the problem of accessibility. However, provisions to limit access to the subsidy to applicants who are financially advantaged are necessary [31]. In this way, reimbursement amounts can be increased, which may improve dentists' willingness to participate in the subsidy program and solve the problem of low availability.

This study has several limitations. The first limitation concerns the sample used in the study. This study uses the elderly dentures subsidy program of Taoyuan City as the research object. Nevertheless, a no exclusion clause in elderly dentures subsidy systems is rare. The generalizability of the results to populations with different socioeconomic backgrounds may be limited. Additionally, in terms of financial support, the government has a budget, and the elderly can ignore affordability. The satisfaction survey after the delivery of the dentures was conducted in an office setting, and reliability may not be high. Therefore, this study does not discuss acceptability. Future research could include the use of a verified structural satisfaction questionnaire for follow-up after the delivery of dentures to supplement the acceptability dimension of access to denture restoration services. Owing to the reasons, this study does not discuss acceptability and awareness as elements of access. Extensive research across the country is necessary to provide further evidence for policy improvement.

\section{Conclusion}

Although the Taiwanese government provides a subsidy to older residents to help them overcome financial barriers to access denture restoration, the problems of insufficient numbers of contracted hospitals and low reimbursement amounts remain in the subsidy program. The two factors affect the elderly's access to denture restoration. However, the available subsidy amount is low. Therefore, the willingness of dental professionals to participate in the subsidy program is also low, which may affect the availability of subsidized services. The government should exclude wealthy individuals and offer the subsidy only to low-income residents. The limited budget provided by the subsidy program should be allocated to low-income elderly individuals with missing teeth who are in dire need of financial support to improve their access to denture restoration services.

\section{Abbreviation}

RPD: Removable partial denture. 


\section{Supplementary Information}

The online version contains supplementary material available at https://doi. org/10.1186/s12913-022-07504-6.

Additional file 1. Data sets

\section{Acknowledgements}

The author would like to thank the Information Department of the Renai Branch of Taipei City Hospital for providing software support during the data analyses and the editor and two anonymous reviewers for their insightful comments that helped improve the manuscript.

\section{Author's contributions}

KY C conceived the study, analyzed the data, and drafted the manuscript. The author has read and approved the manuscript.

\section{Funding}

This study is partially supported by the in-hospital research project of Taipei City Hospital (Grant numbers TPCH-110-27).

\section{Availability of data and materials}

The datasets supporting the method and materials of this article are included within the References section and the additional files.

\section{Declarations}

Ethics approval and consent to participate

This study protocol was approved by the Taipei City Hospital Research Ethics Committee (Grant numbers TCHIRB-11002013-E).

In this study, all the retrospective surveys involving humans were conducted ethically and in accordance with the Declaration of Helsinki. Moreover, participants were de-identified. According to a retrospective study of medical records, the research process will not exceed the minimum risk, and the consent waiver will not adversely affect the rights and welfare of the participants. Thus, the Taipei City Hospital Research Ethics Committee approved the request to waive informed consent.

\section{Consent for publication}

Not applicable

\section{Competing interests}

The author declares that he has no competing interests.

\section{Author details}

${ }^{1}$ Department of Stomatology, Taipei City Hospital Renai Branch, 10629 No. 10, Section 4, Renai Road, Daan District, Taipei City, Taiwan. ${ }^{2}$ University of Taipei, Taipei City, Taiwan.

Received: 19 July 2021 Accepted: 14 January 2022

Published online: 20 January 2022

\section{References}

1. Penchansky R, Thomas JW. The concept of access: definition and relationship to consumer satisfaction. Med Care. 1981;19(2):127-40 https://www. jstor.org/stable/3764310.

2. Aday LA, Andersen R. A framework for the study of access to medical care. Health Serv Res. 1974;9(3):208 https://www.ncbi.nlm.nih.gov/pmc/ articles/Pmc1071804/.

3. Andersen RM, McCutcheon A, Aday LA, Chiu GY, Bell R. Exploring dimensions of access to medical care. Health services research. 1983;18(1):4974 https://www.ncbi.n/m.nih.gov/pmc/articles/PMC1068709/.

4. Weissman JS, Epstein AM. The insurance gap: does it make a difference? Annu Rev Public Health. 1993;14(1):243-70 https://www.annualreviews. org/doi/pdf/10.1146/annurev.pu.14.050193.001331.
5. Saurman E. Improving access: modifying Penchansky and Thomas's theory of access. J Health Serv Res Policy. 2016;21(1):36-9. https://doi. org/10.1177/1355819615600001.

6. Lutz W, Sanderson W, Scherbov S. The coming acceleration of global population ageing. Nature. 2008;451(7179):716-9. https://doi.org/10. 1038/nature06516.

7. Rechel B, Doyle Y, Grundy E, McKee M, Organization WH. How can health systems respond to population ageing. Copenhagen: WHO Regional Office for Europe; 2009. http://repository.essex.ac.uk/id/eprint/20994

8. Harford J. Population ageing and dental care. Commun Dent Oral Epidemiol. 2009;37(2):97-103. https://doi.org/10.1111/j.1600-0528.2008. 00441.x.

9. Kiyak HA, Reichmuth M. Barriers to and Enablers of Older Adults' Use of Dental Services. J Dent Educ. 2005;69(9):975-86. https://doi.org/10. 1002/j.0022-0337.2005.69.9.tb03994.x.

10. Vos T, Abajobir AA, Abate KH, Abbafati C, Abbas KM, Abd-Allah F, et al. Global, regional, and national incidence, prevalence, and years lived with disability for 328 diseases and injuries for 195 countries, 1990-2016: a systematic analysis for the Global Burden of Disease Study 2016. The Lancet. 2017;390(10100):1211-59. https://doi.org/10.1016/S0140-6736(17) 32154-2.

11. de Sire A, Invernizzi M, Ferrillo M, Gimigliano F, Baricich A, Cisari C, et al. Functional status and oral health in patients with amyotrophic lateral sclerosis: a cross-sectional study. NeuroRehabilitation. 2021;48:49-57. https://doi.org/10.3233/NRE-201537.

12. Mack F, Schwahn C, Feine JS, Mundt T, Bernhardt O, John U, et al. The impact of tooth loss on general health related to quality of life among elderly Pomeranians: results from the study of health in Pomerania (SHIPO). Int J Prosthodont. 2005;18(5):414-9 https://research-repository.griffith. edu.au/bitstream/handle/10072/15442/44782.pdf;sequence=1.

13. Yoshida M, Kikutani T, Yoshikawa M, Tsuga K, Kimura M, Akagawa Y. Correlation between dental and nutritional status in community-dwelling elderly Japanese. Geriatr Gerontol Int. 2011;11(3):315-9. https://doi.org/ 10.1111/j.1447-0594.2010.00688.x.

14. Wöstmann B, Budtz-Jørgensen E, Jepson N, Mushimoto E, Palmqvist S, Sofou A, et al. Indications for removable partial dentures: a literature review. Int J Prosthodont. 2005;18(2):139-45 http://www.quintpub.com/ userhome/ijp/ijp_18_2_Wostmann_9.pdf.

15. Quiñonez C, Grootendorst P. Equity in dental care among Canadian households. Int J Equity Health. 2011;10(1):14. https://doi.org/10.1186/ 1475-9276-10-14.

16. Holm-Pedersen P, Vigild M, Nitschke I, Berkey DB. Dental Care for Aging Populations in Denmark, Sweden, Norway, United Kingdom, and Germany. J Dent Educ. 2005;69(9):987-97. https://doi.org/10.1002/j.00220337.2005.69.9.tb03995.x

17. Cheung HH-N, Fong S, Lau DM-C, Mak RL-Y, Man GW-C, So KM-K, et al. Health care voucher scheme and willingness to spend on dental care among Hong Kong elders. Hong Kong Dent J. 2008;5:84-92 http://www. hkda.org/hkdj/N5/N2/v5N2_P84_OA1.pdf.

18. Leake JL, Birch S. Public policy and the market for dental services. Commun Dent Oral Epidemiol. 2008;36(4):287-95. https://doi.org/10.1111/j. 1600-0528.2008.00438.x.

19 Mittal R, Wong ML, Koh GC-H, Ong DLS, Lee YH, Tan MN, et al. Factors affecting dental service utilisation among older Singaporeans eligible for subsidized dental care - a qualitative study. BMC Public Health. 2019;19(1):1075. https://doi.org/10.1186/s12889-019-7422-9.

20. Blackwell DL, Lucas JW, Clarke TC. Summary health statistics for U.S. adults: national health interview survey, 2012. Vital Health Stat 10. 2014(260):1-161. https://europepmc.org/article/med/24819891

21. Huang M-S. Oral Health Survey of Adults and Seniors, 2015-2016. In: Ministry of Health and Walfare ROCT, editor. 2018. https://dep.mohw.gov. tw/domhaoh/cp-486-39243-107.html

22. Tsai C-C, Yang Y-X, Hsieh T-Y, Huang C-D. Survey on oral health of adult and elderly in Taiwan. In: Ministry of Health and Welfare ROCT, editor. 2003. https://dep.mohw.gov.tw/domhaoh/cp-486-1917-107.html

23. Dept. of houshold Registration. Minitry of Interior ROC. Percent Distribution of Population by Three-stage Age Group and Dependency Ratio for Counties and Citiesr 2020 Available from: https://www.ris.gov.tw/app/ portal/346. https://ws.moi.gov.tw/001/Upload/OldFile/site_stuff/321/2/ year/year.html 
24. Welfare MoHa. The current status of medical institutions and the statistics of hospital medical service volume in 2017 2017. https://dep.mohw.gov. tw/dos/cp-4033-42732-113.html Cited 2021. 153

25. Division L-tC. Denture application subsidy Elderly subsidy: Department of public health, Taoyuan; 2021. https://dph.tycg.gov.tw/care/home.jsp?id= 246\&parentpath $=0,241$

26 Van Waas M, Meeuwissen J, Meeuwissen R, Käyser A, Kalk W, Van't Hof M. Relationship between wearing a removable partial denture and satisfaction in the elderly. Community Dent Oral Epidemiol. 1994;22(5PT1):315-8. https://doi.org/10.1111/j.1600-0528.1994.tb02059.x.

27. Nevalainen MJ, Närhi TO, Ainamo A. A 5-year follow-up study on the prosthetic rehabilitation of the elderly in Helsinki. Finland. 2004;31 (7):647-52. https://doi.org/10.1111/j.1365-2842.2004.01280.x.

28. Ćatović A, Jerolimov V, Ćatić A. Tooth loss and the condition of the prosthodontic appliances in a group of elderly home residents. J Oral Rehabil. 2000;27(3):199-204. https://doi.org/10.1046/j.1365-2842.2000.00521.x.

29. Heydecke G, Penrod J, Takanashi Y, Lund J, Feine J, Thomason J. Costeffectiveness of mandibular two-implant overdentures and conventional dentures in the edentulous elderly. J Dent Res. 2005;84(9):794-9. https:// doi.org/10.1177/154405910508400903.

30. Turner M, Jahangiri L, Ship JA. Hyposalivation, xerostomia and the complete denture: a systematic review. J Am Dent Assoc. 2008;139(2):146-50. https://doi.org/10.14219/jada.archive.2008.0129.

31. Harford J, Spencer AJ. Government subsidies for dental care in Australia. 2004;28(4):363-8. https://doi.org/10.1111/j.1467-842X.2004.tb00445.X.

\section{Publisher's Note}

Springer Nature remains neutral with regard to jurisdictional claims in published maps and institutional affiliations.

- fast, convenient online submission

- thorough peer review by experienced researchers in your field

- rapid publication on acceptance

- support for research data, including large and complex data types

- gold Open Access which fosters wider collaboration and increased citations

- maximum visibility for your research: over $100 \mathrm{M}$ website views per year

At BMC, research is always in progress.

Learn more biomedcentral.com/submissions 